\author{
EMERGING VOICES
}

\title{
Crossing Borders in Uniform: \\ The Construction of Subjectivity in a Post 9/11 Blogosphere
}

\author{
Fatima-al-zahraa Ahmad Ramy*
}

\section{Introduction}

In his second inaugural address on January 20, 2005 after being re-elected as a president of the United States for another term, George W. Bush continued to approach contemporary American history through the defining moment of the September 11, 2001 attacks: "For a half century, America defended our own freedom by standing watch on distant borders. After the shipwreck of communism came years of relative quiet, years of repose, years of sabbatical and then there came a day of fire" (NPR 2005). The consequent vicious 'war on terror' caused the deployment of thousands to protect American borders overseas, a sacrifice which Bush made sure not to overlook in his speech at the time: "A few Americans have accepted the hardest duties in this cause [...] the dangerous and necessary work of fighting our enemies. Some have shown their devotion to our country in deaths that honored their whole lives - and we will always honor their names and their sacrifice" (NPR 2005). Although the "names" and "sacrifices" - i.e. the mere announcement of the death - of such soldiers would occasionally be remembered and cherished, what the US president - as many others - unmistakably overlooks is recognizing the 'stories' of such individuals: regarding them as citizens with fully rounded lives to appreciate, and not just names engraved on granite walls and plaques exhibited during memorials. Nevertheless, several of "those in uniform" choose to narrate their own stories instead during their military service away from their homeland using the distinctive literary and media platform of the blogosphere; in particular, this paper examines the blogs "My War: Killing Time in Iraq" by

\footnotetext{
* Assistant Lecturer in the Department of English Language and Literature, Faculty of Arts, Cairo University. This paper is derived from her Ph.D. thesis in-progress, entitled "Individual Narratives as Cultural Interventions: A Study of Selected Blogs" (Cairo University), supervised by Prof. Randa Abou Bakr.

Cairo Studies in English 2020(2): https://cse.journals.ekb.eg/
} 
Colby Buzzell, "Just Another Soldier" by Jason Hartley, and "A Soldier's Thoughts" by Zach. Based on Raymond Williams' notion of "emerging alternative culture" and Robert M. Strozier's theoretical examination of the subject/ed, this paper studies how such self-narratives construct their writers' subjectivities while simultaneously deconstructing the patterns of hegemonic discourse often disseminated in mainstream media outlets.

\section{Creating "diaries" online}

The desire to freely express oneself seems innate in human nature. In almost any given community across history, written recordings -- ranging from early cave scribblings until our modern print and digital documents -- by individuals who strive to both voice and record their own thoughts and feelings as well as share them with their communities could be significantly traced. In cases when such surrounding societies prove stifling through posing any sort of restrictions onto the individual, the latter's yearning towards self-expression is often reciprocally intensified. Trying to understand the motives behind such instinctive inclinations, Pierre Bourdieu explains:

Writing abolishes the determinations, constraints and limits which are constitutive of social existence: to exist socially means to occupy a determined position in the social structure and to bear the marks of it, especially in the form of verbal automatisms or mental mechanisms; it also means to depend on, to hold to and to be held by, in short, to belong to groups and be enclosed in networks of relations which have objectivity, opacity and permanency, and which show themselves in the form of obligations, debts, duties [...] in short controls and constraints. (1996, 27; italics in original)

Thus, writing as activity is primarily geared towards fulfilling one's deep-rooted tendency for self-expression and liberation against a restraining social existence as an act of resistance and self-assertion, an instinctive reaction which Karl Weintraub attributes to the fact that "we are captivated by an uncanny sense that each one of us constitutes one irreplaceable human form, and we perceive a noble life task in the cultivation of our individuality, our ineffable self" (qtd. in Anderson 2010,4). Life writings, in particular, are primarily concerned with the self as Philippe Lejeune defines the genre being any "retrospective prose narrative produced by a real person concerning his own existence, focusing on his individual life, in particular the story of his personality" (qtd. in Smyth 2016, 
2). Therefore, venturing to "document" their own version of reality experienced firsthand as well as share such self-narratives amongst a broad spectrum of readers -- in this case, a global audience of internet users -- the American soldiers/bloggers under study -- through creating new modes of representing selfhood and subjectivity -- profoundly contribute to the shaping of the contemporary American literary and cultural scene.

Although culture, in the first place, is a problematic term to define given its diverse facets in society, Raymond Williams offers a definition from a "documentary" perspective; one that could be regarded as

the body of intellectual and imaginative work, in which, in a detailed way, human thought and experience are variously recorded. The analysis of culture, from such a definition, is the activity of criticism, by which the nature of thought and experience, the details of the language, form and convention in which these are active, are described and valued. Such criticism [...] seeks to relate them [i.e. the works] to the particular traditions and societies in which they appeared. (2003, 28; italics mine)

In modern culture, in particular, a huge body of documentation takes place through online media in an accelerated rate, given not only the ever-developing facilities that technology offers every day but also the increasing rates of accessibility worldwide. According to the latest statistics by the United Nations' agency for Information Technologies in 2019, over $53 \%$ of the world's population has access to Internet services with, more specifically, "70 per cent of the world's youth being online" (Sanou 2017, n. pag.). Hence, new writing "forms" have consequently arisen, creating their own remarkably growing audiences. Furthermore, this, inevitably, creates new dynamics in literary writings in specific as Williams observes that from a "historical perspective ... the crisis of literature in the second half of the twentieth century is due to changing processes and relationships, changes in the publishing industry, and other forms of communication. [...] This is not only a matter of new technologies but one of deep changes in social organization and social practice" (qtd. in O'Connor 2006, 82). Therefore, online written productions have rapidly gained popularity lately, having the internet as an alternative venue away from the many restrictions of the traditional publishing system.

Although digital literary production has undeniably proliferated in the last two decades, on a yet closer look, however, it is almost instantly noticeable how 
a large body of produced content relies on narratives of the self. This is only a natural outcome given how intrinsic individuality is to the usage of new media: "In the more media studies-inflected end of literary studies there has also emerged work regarding nonfiction bloggers and identity-construction via interaction on social media. Yet, such works hew closer to life-writing modes of analysis than fiction-based models" (Murray 2018, 28). The inclination users find towards narrating their everyday life experiences helps them assert their distinctive individualities within their communities through free and direct selfexpression. This is significantly in line with the opportunities the digital sphere offers for users to freely present and shape their individualities in any way they would create for themselves:

The burgeoning of online self-expression is shaping new projects of self-presentation. Some, such as blogs, adapt written genres of selfwriting. Other mixed-media forms such as social networking sites generate composite modes of digital life narrative. Yet others, such as massively multiplayer online games, use avatars that allow users to reimagine themselves -- with different gender, ethnicity, and/or bodily features. (Smith and Watson 2010, 183)

Thus, one distinctive mode of writing online is a blog, which allows its writers to remodel their own identities while celebrating their newly found personal spaces in a virtual world, often lacking in the real one.

Blogs date back to the late 1990s after which they have become "so widely recognized that Merriam-Webster listed blog as its Word of the Year in 2004" (Andrews 2007, 51). Writers preferred the blogosphere because with "little technical background" and "generally at no cost" (51) they could create their own personal blogs where they could express themselves freely and receive feedback from their audience as well without any forms of constraint or censorship. Therefore, this study aims at examining blogs as alternative media and a powerful agent shaping today's popular culture.

\section{Individual Agency}

Like 'culture,' popular culture is, similarly, challenging to define; however, one influential interpretation of the term is offered by John Fiske, highlighting, above all, the resistive quality of popular culture: "[it] is the culture of the subordinated and disempowered and thus always bears within it signs of power relations, traces of the forces of domination and subordination that are central to 
our social system and therefore to our social experience. Equally, it shows signs of resisting or evading these forces" $(2010,4)$. Therefore, the blogs under study will be primarily examined in light of what Raymond Williams refers to as 'emergent' alternative culture:

By 'emergent' I mean, first, that new meanings and values, new practices, new significances and experiences, are continually being created. But there is then a much earlier attempt to incorporate them, just because they are part -- and yet not a defined part -- of effective contemporary practice. Indeed it is significant in our own period how very early this attempt is, how alert the dominant culture is to anything that can be seen as emergent. (Williams 1980, 41)

Thus, the resistive quality of the blogs is inarguably foregrounded as their authors refuse to accept the views spread via mainstream media as 'the' only acceptable representation of reality despite the censorship often imposed by dominant power structures; on the contrary, they exert significant individual effort in order to find for themselves other perspectives to reality and share it with a worldwide audience whom they passionately await its interaction in return.

In his blog "A Soldier's Thoughts," an Infantry sergeant named Zach who also served as an Arabic translator in Iraq chooses to foreground an introductory "disclaimer" to his readers on the front page asserting, "ALL opinions expressed on this blog are those of myself in my private capacity and not as a representative of the DoD [Department of Defense], DA [Department of the Army], or any particular element of the Government" (n. pag.). Yearning for individual selfexpression, Zach's posts are mostly blunt, first-hand experiences of the war in which he criticizes the indifference of power structures to the lives wasted in futile bloodshed. In a post dated July 18, 2006, and with a satirically interrogative title "This is OUR world?", Zach blames policy makers for the violence he witnesses against civilians:

The way I see it we need to be getting out of Iraq, and fast. [...] We cannot control that country with our backward politicking and poor planning. Unfortunately it is not the soldiers and paramilitary organizations taking the brunt of the attacks, instead it is the civilians (aka non-combatants). Yeah, we aren't the ones doing the targeting of civilians but what can we do if we cannot stop the violence against 
them, should we stay there and let it get so much worse because of our occupation? [...] What is a country to do? I believe that to be a true patriot you must not allow wrongful decisions to continue to be made [...] As we look at our future in Iraq we realize that we are there for the long haul because someone doesn't want to even think about a possible timeline of withdrawal. (Zach 2006, "This is OUR world?")

The new meanings and significances being constantly created which Williams refers to as one of the major tenets within an "emerging" cultural product are evident through Zach's inquisitively confrontational attitude towards decision makers responsible for his intolerable existence. His defiant language is a stark criticism of an alternatively complacent mainstream discourse which often validates and consolidates such indifferent attitudes towards individuals. In another post entitled, "A Short Walk Through My Thoughts," published January 26, 2006, Zach, on a more reflective note, gives voice to his silenced apprehensions:

I don't know why I chose this story to write about but my thoughts often turn to my friends who weren't as fortunate as me. Mayhap I have forgotten the face of my father but I think not. Things go slower here on the peaceful side but don't ever let that fool you, for like a river through a valley the politicians are constantly wearing away our rights through the patriot act and other such things. Just look at how they deny death benefits for those soldiers who had to purchase their own body armor due to shortages. (Zach 2006, "A Short Walk")

Similarly, the sarcastic remarks implied within are again a powerful stance towards appreciating and memorializing the individual lives of those whom media conglomerates would hardly ever recognize as worthy of attention, but who, on the contrary, are foregrounded in a blogger's narratives as the major criterion upon which war is to be continued or put to an end. An inside view of how things are on the ground as well as the intricate details of people's existence is highlighted in a resistive move against a seemingly systematic disdain to the worth of every individual life.

However, in a more vicious reaction persistently waged by a negligent power structure, censorship is a major impediment to such individual narratives that give voice to the more voiceless, and often silenced, sectors of a community. In 
his blog "My War: Killing Time in Iraq," Colby Buzzell, not just a soldier, but a journalist by profession as well, starts communicating his experiences while serving in Iraq since 2004. His posts are an unapologetic criticism of several mainstream narratives that impose specific representations of the reality of the ongoing war while discrediting others. Instead of defending his homeland against some prescribed enemies, he only finds himself deserted in a foreign land, struggling with the heaviness of ongoing violence. While venturing to communicate such a view to his readership, the "alertness" of a dominant culture as Williams describes at once hinders such a process in the form of direct censoring: "I noticed there were some media reports and the Army was saying, 'We're not trying to censor soldiers and they have freedom of speech,' [...] And I was like, 'No, they don't. That's full of crap. Soldiers don't have freedom of speech"' (Buzzell 2006). Lack of transparency is equally extended to include mainstream media platforms of which Buzzell's first hand experience introduces him to the selective versions of reality that such corporates choose to disseminate: "I'm a journalist; I work [so hard] to try to be objective. But it's hard to say that CNN is objective, the New York Times is objective, when I have been there and observed the same thing come out as a totally different story. It's hard to say the national media is always objective" (Buzzell 2006). Such posts have caused the blogger's narratives to be abruptly cut off at times. Another soldier blogger, Minnick -- who considers Buzzell "the Rosa Parks of milblogging" -- comments on the reactions to such suppressive acts asserting: "it was a very sad deal. Nobody wanted to see that happen-everybody even within the ranks. I was there, I heard the meetings and things that were said about him. Everybody thought what he was doing was good for the Army and was especially good for people back home. He brought a side of war that people didn't get to see. The way he wrote was so present tense and it was so free from editing or censorship. [...] They didn't know how to contain him, so they just stopped him" (qtd. in Buzzell 2006).

Hence, focusing on blogs as an efficient online media platform, Chris Atton argues that alternative media at large is "crucially about offering the means for democratic communication to people who are normally excluded from media production. They are to do with organizing media along lines that enable participation and reflexivity" (Atton 2002, 4). Therefore, in minimizing censorship and publishing constraints as well as instantly connecting bloggers with internet users, the blogosphere acts as a competent substitute to traditional media ensuring higher levels of transparency and immediacy in dealing with its audience through the interactive qualities offered by Web 2.0 (i.e. internet with 
user-generated content). In brief, Atton highlights three terms introduced by Raymond Williams concerning "democratic communication" and which Atton believes are essential in appreciating the role of alternative media productions: "decapitalization, deprofessionalization and deinstitutionalization" (Atton 2002, 4). In other words, produced at almost no cost by ordinary individuals in society, alternative media is a notable venue for self-expression and the dissemination of views and knowledge. Atton also introduces the term 'alternative internet' through which he assumes that blogging sites "may not actually present politically charged content, but their manner of collecting and circulating information construct a process and content that are alternative to the mainstream of corporate conglomerates" (qtd. in Atkinson 2010, 18). Moreover, since "most blogging is to some extent self-representational, and as such a form of lifewriting and autobiography" (Rettberg 2008, 111), blogosphere narratives are, therefore, in essence an enhancement of the construction of subjectivity of such bloggers within their own communities through the delineation of personal incidents that give readers a closer insight into the lives of individuals that are often forgotten or overlooked.

\section{The Construction of Subjectivity}

Referring to the exclusive existence of each human life and its instinctive inclination towards self-assertion and realization, the terms "subjectivity" and "individuality" are often used interchangeably; however, a more profound, and etymologically driven enquiry easily uncovers a world of difference between both terms. In his seminal book, Foucault, Subjectivity, and Identity: Historical Constructions of Subject, Robert M. Strozier explains how Michel Foucault understands the term "individual", derived from the Latin individuum, to simply signify the singularity of one's physical existence or, more specifically, "the human material entity (including mind); ... the stage prior to becoming a subject, that is, a cultural subject" (Strozier 2002, 9). Thus, Strozier offers, on the other hand, an extensive dissection of the word "subject" which goes back to the Latin verb subicio or subjicio literally meaning "to place near or under" (11). Ironically, however, two juxtaposed substantives have been derived from this same verb.

First, subjectum meaning " that which is spoken of, the foundation or subject of a proposition' -- that is, that which has already been placed under" (Strozier $2002,11)$. According to this definition, the notion of the subject is regarded as "a foundation or as an origin of thought, action and change. This subject is the a priori, the pre-existent platform or basis from which thought, action, and reaction 
emerge" (11); thus, such an understanding essentially promotes the agency of each individual within their social surroundings, viewing them as influential subjects. Second, subjectus, derived from the past participle referring to "an inferior, subject' -- that is, subject-ed or subjected to something prior" which, on the contrary, assumes that the subject is, in fact, the outcome of "some enculturating process" which lends individuals a rather passive role in shaping their own milieus. In other words, the former subject is a given that is able to produce culture and knowledge, while the latter is produced by culture (10-11). Thus, in light of such a dichotomy, the bloggers' life-writings could efficiently serve as a means towards reconciling both seemingly conflicting roles that are inevitably embedded within the bloggers' existences as social subjects. Their personal narratives are, above all, a declaration of their unique and distinctive life experiences through which each writer's subjectivity is solidly constructed within an extended global society, -- i.e. the blogosphere -- attempting to resist dominant cultural practices enforced by hegemonic socio-political discourse.

Thus, trying to understand the dynamics shaping the relationship between subjectivity and its role in defining world culture is a necessary quest worthy of profound investigation, especially in its modern evolution. Pursuing a historical approach to understanding such a relation, Strozier continues to explain how Foucault's view of the modern world stresses the shift that took place particularly after the 18th century: "with the 'death of the king,' real or supposed, a somewhat different version of this subject has emerged. Foucault argues that monarchy has given way in the modern age to a power-knowledge network of discourses ... and disciplines ... to which the modern individual is necessarily submitted in order to be produced as a cultural subject, [...] a "discursive subject"" (Strozier 2002, 12). In other words, a modern "subject" is at once subjected to authoritative discourse and mindsets widely spread in society by certain powerful institutional entities, while simultaneously attempting to fiercely resist such forces through asserting one's agency and influence. Therefore, although the subjectus is produced by being "'brought under' a disciplinary or cultural apparatus or "subjected to" a dominant regime, the subjectum, on the other hand, entices individuals to function as the foundation or origin of subversive human action; to realize a "self-founding subjectivity" (12). This is based on the assumption viewing the subject as a unique existence: "we are self-founded as individual subjects or selves as a given. We actualize this potential by self-reflective insight: we have the capacity to stand outside ourselves, examine the cultural forces acting upon us, and to find our true selves in contrast to this alien other" (12). 
Therefore, although the bloggers under study are all an embodiment of the "subjectus" by affiliation, they, nevertheless, succeed to go beyond that role and represent a newly founded "subjectum" in which their personal life-writings are an exploration of individual voice and worth. Several of their posts are selfreflective in essence, a scrutiny of their inner conflicting sentiments towards the ongoing war, a psychological inspection which further highlights the individualistic approach of their narratives. With the title "I Ask You," Zach publishes a post where he seeks answers to his suffering conditions not only from his family members, readers, or society at large, but his own self in the first place:

Are you proud of me Mother? I am a soldier. Are you proud of me Father? I have killed. To my country I ask you, are you proud of me? [...] These hands of mine know how to destroy and leave my mess for others to pick up. At times I feel that the only thing I have left behind me is a path of broken pieces. Perhaps that is my legacy, to shatter what others (including myself) hold dear. [...] You know the best part? The sorrow and pity I feel afterwards. Isn't it ridiculous? You would think that I would be the last one to cry for the casualties I have helped cause. [...] I am still alive and like all living things, with each breath I come closer to death. I walk this path alone and [have no idea] where it leads. (Zach 2005)

Similarly suffering from the ferocity of a ruthless battle taking place on the outside, Jason Hartley's blog, "Just Another Soldier" yearns towards delineating a yet more vicious encounter with one's own self. As he chooses to name his blog, Hartley's focus is on the individual stories he witnesses firsthand, while being aware of how insignificant such stories are often regarded in mainstream media, he sarcastically refers to himself as just another one of those overlooked individuals. In a post published on April 24, 2004, and sarcastically entitled "I Dead Civilians," Hartley intimately discloses to his readers one traumatic experience:

As I try to fathom what it must feel like to be a poverty-stricken eight-year-old girl and experience the epic pain of having your family suddenly and violently killed in front of you, I have to pause and ask myself, Now what am I doing here again? I know this kind of thing happens in combat and I kind of expected to see it, but Jesus, 
the record is pretty bad so far. [...] I've been stewing over this dead family thing for a couple weeks now. I've been painstakingly mulling over in my mind the things these insurgents do and the things we do and the unintuitive peculiarity of how the drive to be violent seems to precede the purpose to be violent and how rampant it is to meaninglessly develop one's identity through injury, but frankly I don't think I've figured it all out well enough yet to even kludge together a coherent line of thought. [...] But what does any of this have to do with the dead family you ask? Well, nothing directly. It's just another one of those things I'm having difficulty reconciling in my mind, I guess. (Hartley 2004; italics in the original)

Such posts are a remarkable reminder for readers of the narrative approaches of such mode of life-writing which is primarily geared towards empowering a passive "subjectus" into an actively represented "subjectum" through its perpetual endeavours to make sense of a seemingly senseless state of life. Therefore, emphasizing the subjective nature of the self-writings, Sean Dustman, also a milblogger, proclaims: "Don't attach stereotypes to us. Military members come from all walks of life and we have different outlooks on the world at large. I believe my core values will hold up with the best of them. I'm a complex person, just like the rest of you. I don't always agree with our missions but I signed on the dotted line and once my name was on that piece of paper, when the brass says jump, I say how high. ... I don't attack people but I do attack ideas" (Dustman 2004). Hence, the bloggers are in constant spontaneous communication with their audience to which they try to delineate not only what they witness firsthand, but, more importantly, how they are not to be stripped of their citizenship rights -- for merely being in service overseas -- as any of those who are still back home. Since "no other military in world history has been deployed as widely as that of the US," according to the Heritage Foundation reports (qtd. in Smith 2012, 368), the bloggers resist attempts to overlooking them as American citizens into the stereotypical representations affiliated to them as mechanical representatives of collectivism or homogeneity.

\section{Beyond the "dog tags"}

Focusing on the importance of citizenship as a pronouncement of individual autonomy, Etienne Balibar regards what he termed the 'citizen subject' or 'the political subject' as an influential agent that could actively affect change in modern society. Despite being exposed to certain socio-political power 
structures, individuals could still, nevertheless, preserve their rights of selfassertion and independence as stipulated by their citizenship status:

If the individual is necessarily both citizen and subject, this necessity is inscribed in the fact that he is subject not to the will of another but to a law of which he as citizen is the maker. Because the sovereign is made up of all individuals in a condition of association, every one equal to every other one, equally 'above' the law as its maker and under it as a legal subject, the citizen's relation to the law is one of immanence: the activity of the citizen (the making of law) is one and the same thing as the citizen's passivity (obedience to the law). The immanence of this relation (or even this antimony) vanishes as soon as inequality appears, even if it applies only to the person of the sovereign who would then become the only citizen in a world of subjects. (Montag and Elsayed 2017, n. pag.)

The repercussions of such a disturbance and "inequality" are what inevitably drive individuals to activate their roles as resistive agents against threats of discrimination or hegemony. Among the diverse facets of resistance chosen by individuals to emphasize their subjectivities in the face of institutional dominance is the personal documentation of life experiences and "subjective" views and sharing them amongst other members of the society.

Thus, the resistance often achieved by blogging reserves the genre a special position in "citizen media" which is defined by Mona Baker and Bolette B. Blaagaard as one that

encompasses the physical artefacts, digital content, practices, performative interventions and discursive formations of affective sociality produced by unaffiliated citizens as they act in public space(s) to effect aesthetic or socio-political change or express personal desires and aspirations, without the involvement of a third party or benefactor. [...] It also comprises the sets of values and agendas that influence and drive the practices and discourses through which individuals and collectives position themselves within and in relation to society and participate in the creation of diverse publics. $(2016,16)$ 
Baker and Blaagard formulate this definition in light of the Habermasian principle of the "public sphere" which is a realm in which people "may freely engage in debate about issues that concern them, and where 'access' is guaranteed to all citizens" (Baker et al. 2016, 3). Thus, the blog as a digitized form of self-narratives that allows both writers and their readers such access and potential for debate proves itself as a democratic public sphere that enhances its citizens' agency and assertion of their individualities:

The impact of digitization, online interaction and mobile media in recent years [...] [proves] that the public and systemic spheres are discursively interlinked. [...] Unaffiliated individuals may now engage in political conversation as easily as Members of Parliament and can cumulatively shift the 'systemic' agenda by posting photographs and comments or by recording and uploading visual records of a first-hand experience using their mobile devices. This multiplicity of voices and tenors, technologies and media platforms, inevitably challenges the idea of the public sphere as one unifying space. $(2016,4)$

Resistance extends even to blogs' generic function as it opens up new arenas to literary writings of the self, away from the restrictive sphere of print publications; they are an effective way "of harnessing the power of digital selfpublishing to rescue literature from the hierarchical and tightly patrolled world of print and to move it into the mainstream of contemporary online life" (Hammond 2016, 142). Therefore, examining blogs as cultural products is essential in understanding its role in shaping media nowadays. In his seminal work, Firing Back: Against the Tyranny of the Market, Pierre Bourdieu explains how traditional media 'products' are often culturally and economically manipulated:

Far from promoting diversity, competition breeds homogeneity. The pursuit of audience ratings leads producers to look for omnibus products that can be consumed by audiences of all backgrounds in all countries because they are weakly differentiated and differentiating. [...] The key point, however, is that commercial concerns, the pursuit of maximum short term profit and the 'aesthetic' that derives from that pursuit, are being ever more intensely and widely imposed on cultural production. The 
consequences of such a policy are exactly the same in the field of publishing, where very high concentration of ownership is also found." (2003, 68-9; italics in original)

Thus, blogs could serve as an efficient alternative that promotes self-assertion against a vicious constraining 'market' through offering writers the chance to voice their personal opinions and narratives to a world-wide audience.

\section{Idiosyncratic Features of Blogosphere Narratives}

Axel Bruns' analysis of the rise of the Internet as a mass medium, unlike previous mass media, introduces several challenges to the traditional, industrial model of information production and distribution $(2008,13)$. First, an obvious difference is evident in terms of the mechanism of access itself; access to digitized information sources "takes place on an information-pull basis rather than the product-push model of the traditional broadcast and print mass media" (13). Second, individuals getting access to the means of producing and distributing such information is another major factor where its availability facilitates the users' public sharing of their personal narratives: "rather than limited to a small number of operators ... consumers themselves can now become active producers and distributors of information" (13). Therefore, usage of the internet is often referred to as 'produsage' as an amalgamation of the roles of both 'producers' and 'users' is manifested; both now function as "nodes in a neutral network and communicate with one another on an equal level. ... This is particularly empowering for users, who now have access to a greater range of tools to network and build communities among themselves, away from the topdown mediated spaces of the traditional mediaspheres" (14). Third, audience participation is exclusively and instantly offered as well since internet technology "enables peer-to-peer modes of organizing the collaborative engagement of communities in shared projects: this means that users can now communicate and engage directly with one another on a global scale, entirely bypassing traditional producers and distributors of information" (13). This facility helps activist bloggers, for instance, immensely in communicating their self-narratives to a global audience which could further promote their causes at a larger scale. Finally, Bruns highlights a quality of digital technology as a cultural product, adding that "in its digital form, content (whether representing information, knowledge, or creative work) is easily and rapidly shareable ... this means that the term 'consumption' in its conventional sense no longer applies, as digital information is a non-rival good which is not consumed (used up) as it 
is used" (2008, 13-4; italics in original). Therefore, economically, digitized media genres have formed a "networked," instead of an "industrial," information economy with the latter majorly efficient, since the second half of the nineteenth century and throughout the twentieth century (14). Thus, this new economy is primarily characterized by "decentralized individual action" and, more specifically, "new and important cooperative and coordinate action carried out through radically distributed, non-market mechanisms that do not depend on propriety strategies" (Benkler 2006, n. pag.). Blogging, therefore, is resistive to several constraining social and economic norms in both form and content.

Moreover, the act of narration itself has its own distinctive features in blogs. First and foremost, it is often episodic and incoherent since it stems from the writer's spontaneous urge towards documenting everyday life experiences: "In blogs, the reader usually does not find complete stories with a beginning and an end; rather they tend to resemble more of a column or a short story. Typical blog texts take the form of self-expression and consist of informal descriptions of thoughts or events and do not have a thoroughly planned plot" (Lenze 2018, 18). Hence, a conscious and attentive reader is required to be able to create a vital interactive experience with the bloggers. This in turn sheds light on another essential feature exclusive to blogging, namely social interaction. Its inherent potential towards an active participation amongst its agents, both writers and readers, dismisses the element of a passively receptive audience present in earlier forms of self-narratives; "airing deeply personal experiences and thoughts ... [t]he majority of blogs, however, are unlike online diaries in that they are interactive sites for communities that allow users to comment by raising questions, offering the comfort of shared experience" (Smith and Watson 2010, 183). The rewards of such interaction are sensed not only by bloggers but by the site's visitors. "The consumption of others' 'real' lives fulfills a need for people to enter into the lives of others, to 'try' on various identities, to understand one's own identity, and to confirm and affirm one's own life experiences" (Rodrigue 2012,39). Third, most blogs make use of multimedia facilities including images, hyperlinks, videos and sound bites to mention some (36). This multimodality comments on the increasing popularity of the genre as well as the richness of the blogging experience at large:

Some blogs are more than just a listing of items; they have an interactive feel to them. Perhaps there is a marquee with news items scrolling or perhaps certain popular entries are highlighted and being rotated through cyclically. On some blogs it may be possible to rate 
items, and this rating can serve as a measure of the popularity of an entry. [...] The number of tweets made about an entry could also be factored into such a rating. (Rodrigue 2012,37)

Finally, the liberty that users experience while freely voicing their personal opinions is remarkably evident through both the production of, and feedback towards, the delineated narratives by both writers and audience respectively; as a result, an 'uncensored' version of the self is revealed:

All bloggers highlight the freedom of letting out what bothers them
or makes them happy as a highly rewarding feature of their blogging
practice. In addition, another internal reward is the strengthening of
the bloggers' self-reflectivity. Externalising and trying to formulate
thoughts for the blog offers the possibility to become more self-
critical. (Jurkiewicz 2018, 211)

Therefore, such unique idiosyncratic elements of blogging help writers, and audience, immensely towards asserting their own individualities inside society.

The yearning for freedom, which at times necessitates rebellion against constraining social norms, is what emphasizes the resistive quality of blogs. The genre provides writers with a liberal space where they could bring up, comment on, narrate, or interactively discuss any topic regardless of its sensitivity. Such blogs encourage the sharing of self-experience and promote a view of the self as flexible, responsive, and dynamic. They enable users "in remote areas to discuss [issues] which may promote greater education and foster resistance to repressive community norms" (Smith and Watson 2010, 184). Therefore, blogging has been connected in different ways to social and political activism; several selfnarrative bloggers employ the genre to promote their personal stands believing that both "blogging and activism display a set of similar practices, such as writing, discussing or disseminating ideas and arguments for specific causes" (Jurkiewicz 2018, 202). An inevitable inclination towards journalistic writing often is the case, consequently, because activist bloggers do not merely narrate their own lived experiences, or their personal view of certain incidents, but they also necessarily report those specific incidents which they witness first-hand to their readers; even though it is 'their' own version of reality, every account, nevertheless, is essential in providing a holistic picture of any given event while taking into account diverse viewpoints of the individuals involved. This act of both reporting and commenting on incidents allows bloggers to expand their 
readership since "articles can be posted on the blog and thus be used for promoting the blogger's journalistic writings" (Jurkiewicz 2018, 204). Moreover, blogging could further intersect with the sphere of journalism, since both primarily depend on written text to communicate with their audience, thus each genre mutually enriching the other: "blogging is also a catalyst for writing. [...] Constantly writing for and publishing on the blog provides exercise in writing as the basic journalistic skill" (204). Therefore, several bloggers evolve their writings into books such as Colby Buzzell who also published two books My War: Killing Time in Iraq (2006), and Lost in America: A Dead-End Journey (2011) or Jason Hartley's Just Another Soldier: A Year on the Ground in Iraq (2009).

Despite the multitude of American blogosphere narratives created in the aftermath of $9 / 11$ that is beyond any single study or examination, the search for subjectivity as well as the resistive approaches to the different types of hegemony, censorship, or patronizing, are at the core of the majority of such digital cultural products. Therefore, the yearning towards exploring different versions of reality other than those imposed by mainstream alternatives might be summed up in what Paul Woodward, a British journalist, living in the United States, proposes in his blog "War in Context: with attention to the unseen" where he explains:

After 9/11, the Middle East - seen through American eyes inflamed by fear and anger - took on an amorphous, undifferentiated otherness. The threat was called "terrorism" but really it was the unknown. And because we couldn't isolate it, suddenly it seemed to be everywhere. [...] War in Context, from its inception, has been an effort to apply critical intelligence in an arena where political judgment has repeatedly been twisted by blind emotions. It presupposes that a world out of balance will inevitably be a world in conflict. (Woodward 2002)

Thus, forming this blog as a personal initiative attempting to scrupulously study overlooked details in stories conveyed by most media corporations -- hence giving "attention to the unseen" -- is an act of resistance against political and cultural hegemony, and an alternative venue where impartial audiences could find different perspectives to events based on the blogger's first-hand experiences or his individual, disinterested research in analyzing often perplexing current events. Woodward's endeavour, among others, was 
noticeably appreciated by the American public who followed blogs closely, during post 9/11 military actions. Upon studying such an inclination, it was noted that although "individual blogs are not always the ultimate in terms of neutrality and objectivity, but, exactly because of their specificity, engagement, and subjectivity, they are able to challenge hegemonic representations and discourses and articulate a more personal and, some would claim, a more genuine account of war" (Bailey et al. 2007, 151).

\section{Works Cited}

Anderson, Linda. 2010. Autobiography. New York: Routledge.

Andrews, Michael. 2007. "What is a blog?" Business Law Today 16, no. 3 (January/February): 51.

Atkinson, Joshua D. 2010. Alternative Media and Politics of Resistance: A Communication Perspective. NY: Peter Lang.

Atton, Chris. 2002. Alternative Media. London: SAGE.

Bailey, Olga G., Bart Cammaerts and Nico Carpentier. 2007. Understanding Alternative Media. Berkshire: Open University Press.

Baker, Mona and Bolette B. Blaagaard. 2016. "Reconceptualizing Citizen Media: A Preliminary Charting of a Complex Domain." Citizen Media and Public Spaces:

Diverse Expressions of Citizenship and Dissent, edited by Mona Baker and Bolette B. Blaagaard, 1-22. New York: Routledge.

Benkler, Yochai. 2006. The Wealth of Networks: How Social Production Transforms Markets and Freedom. London: Yale University Press.

Bourdieu, Pierre. 2003. Firing Back: Against the Tyranny of the Market. Translated by Loïc Wacquant. London: Verso.

-----. 1996. The Rules of Art: Genesis and Structure of the Literary Field. Translated by Susan Emanuel. Stanford: Stanford University Press.

Bruns, Axel. 2008. Blogs, Wikipedia, Second Life, and Beyond: From Production to Produsage. NY: Peter Lang Publishing, Inc.

Buzzell, Colby. 2006. My War: Killing Time in Iraq (blog). $<$ https://cbftw.blogspot.com/2006/>.

Dustman, Sean. 2004. "Hire me and other holiday wishes!" Doc in the Box (blog).

December 13, 2004. <https://docinthebox.blogspot.com/2004/>.

Fiske, John. 2010. Understanding Popular Culture. London: Routledge.

Hartley, Jason Christopher. 2004. "I $\vee$ Dead Civilians." Just Another Soldier (blog). April 24, 2004. <http://www.justanothersoldier.com/?m=200404>.

Hammond, Adam. 2016. Literature in the Digital Age: A Critical Introduction. New York: Cambridge University Press. 
Jurkiewicz, Sarah. 2018. Blogging in Beirut: An Ethnography of a Digital Media Practice. Bielefeld: Verlag.

Lenze, Nele. 2018. Politics and Digital Literature in the Middle East: Perspectives on Online Text and Context. NY: Palgrave Macmillan.

Montag, Warren and Hanan Elsayed. 2017. Balibar and the Citizen Subject. Edinburgh: Edinburgh UP.

Murray, Simone. 2018. The Digital Literary Sphere: Reading, Writing, and Selling Books in the Internet Era. Baltimore, MD: JHU Press.

NPR. 2005. "President Bush's Second Inaugural Address." January 20, 2005. $<$ https://www.npr.org/templates/story/story.php?storyId=4460172>.

O'Connor, Alan. 2006. Raymond Williams. NY: Rowman \& Littlefield Publishers, Inc.

Rettberg, Jill Walker. 2008. Blogging. Cambridge: Polity Press.

Rodrigue, Tanya K. 2012. "Postsecret as Imagetext: The Reclamation of Traumatic Experiences and Identity." The Future of Text and Image: Collected Essays on Literary and Visual Conjunctures, edited by Ofra Amihay and Lauren Walsh, 39-68. Newcastle: Cambridge Scholars Publishing.

Sanou, Brahima. 2017. "ICT Facts and Figures 2017." International Telecommunication Union, UN. <http://www.itu.int/en/ITU-D/Statistics/ Pages/default.aspx $>$.

Strozier, Robert M. 2002. Foucault, Subjectivity, and Identity: Historical Constructions of Subject. Detroit, MI: Wayne State University Press.

Smith, Hedrick. 2012. Who Stole the American Dream? NY: Random House, Inc.

Smith, Sidonie and Julia Watson. 2010. Reading Autobiography: A Guide for Interpreting Life Narratives. Minneapolis: University of Minnesota Press.

Smyth, Adam. 2016. A History of English Autobiography. New York: Cambridge University Press.

Williams, Raymond. 2003. "The Analysis of Culture." Culture: Critical Concepts in Sociology, volume 2, edited by Chris Jenks, 28-32. London: Routledge.

-----. 1980. "Base and Superstructure in Marxist Cultural Theory." Culture and Materialism: Selected Essays, edited by Raymond Williams, 31-49. London: Verso.

Woodward, Paul. 2002. War in Context: with attention to the unseen (blog). January 2002. <http://warincontext.org/about/>.

Zach. 2005. "I Ask You." A Soldier's Thoughts (blog). December 1, 2005. $<\mathrm{http}: / /$ misoldierthoughts.blogspot.com/2005/12/>.

-----. 2006. "This is OUR world?" A Soldier's Thoughts (blog). July 18, 2006. $<$ http://misoldierthoughts.blogspot.com/2006/07/>.

-----. 2006. "A Short Walk Through My Thoughts." A Soldier's Thoughts (blog). January 26, 2006. <http://misoldierthoughts.blogspot.com/2006/01/>. 